\title{
Visual Analysis within 3D Hand Scanning to Ensure the Reliability and Precision of Anthropometric Data Collection
}

\author{
Emily SEIFERT, Linsey A. GRIFFIN* \\ University of Minnesota, St. Paul, (MN), USA \\ https://doi.org/10.15221/21.42
}

\begin{abstract}
Three-dimensional hand scanning relies on participants to hold a position for a certain amount of time. Any involuntary movements or posture changes can lead to distortions in the three-dimensional scans. When color-capture is possible, clear visible landmarks are needed to create reliable digital landmarks and to take accurate digital measurements. Visual analysis of three-dimensional scanning to assess scan quality for anthropometric data collection is not often considered. However, the quality of the scan can greatly affect the reliability and precision of the anthropometric measurements. This study examined a visual analysis of the three-dimensional hand models provided from two (2) full-color hand-held three-dimensional scanners (the Occipital Structure Sensor and Artec Leo) in the post-processing stage to determine the threedimensional visual reliability and three-dimensional visual precision for twelve (12) participants. The PostProcessing Visual Analysis Likert Scale, developed by Juhnke, Pokorny, and Griffin (2021) [1], was used to provide clear definitions for each location to quantify the scans' overall quality within the visual assessment. This study found that the Occipital Structure Sensor and Artec Leo are comparable within the visual reliability and visual precision analyses at all locations, except for the Visibility of Landmark location. The visual reliability and precision analyses were crucial to understanding where the quality of the scans taken by both scanners might affect the outcomes from the anthropometric data collection. This study provides a method of visual analysis of the three-dimensional models provided by three-dimensional scanners to determine the three-dimensional visual reliability and three-dimensional visual precision for better anthropometric data collection outcomes.
\end{abstract}

Keywords: Three-dimensional full-color hand scanning, Visual analysis

\section{Introduction}

The use of three-dimensional (3D) scanning has become an increasingly viable method for capturing anthropometric data of the hand. A wide variety of 3D scanners have been validated for or have previously been used to collect anthropometric data from the hand [2, 3, 4, 5, 6, 7, 8, 9]. However, during the 3D scanning process, any involuntary movements or posture changes can lead to distortion in the 3D scans gathered and could create errors within the data produced. Therefore, it is essential that researchers have a method to quantify the visual analysis of 3D hand scans to ensure accurate 3D measurement analysis.

\subsection{Visual Analysis in 3D Hand Scanning}

Visual analysis occurs within 3D hand scanning, whether quantified or not, as 3D collection relies on assessing the scans' quality. The visual assessment of 3D hand scans was mentioned within most of the previous comparison studies reviewed for this study [2, 4, 8, 9]. One of the most detailed descriptions of visual analysis for 3D scanning occurred in Dunbar \& Chapates (2019) [9]. Since the 3dMD Full Motion Capture Photogrammetric System with 3dMDhand set-up captures multiple frames, each frame was reviewed, and the best surface mesh was visually selected out of these frames to measure. The best surface mesh was defined as free of stray points, uniform mesh size, free of any artificial "webbing" between the fingers, and free of errors in mapping the 2D color texture on the surface [9]. While visual assessment of scans is common, a systematic framework is needed to ensure accurate data collection.

\subsection{Purpose}

The purpose of this study was to examine a visual analysis of the 3D models provided from the two (2) fullcolor hand-held 3D scanners (the Occipital Structure Sensor and Artec Leo) that occurred in the postprocessing stage to determine the $3 \mathrm{D}$ visual reliability and $3 \mathrm{D}$ visual precision.

*Igriffin@umn.edu 


\section{Method Development}

\subsection{Overview}

The method development of this study includes information on the participants, landmarks, tools, and data analysis. These methods were tested previously in a pilot study with (1) test hand model to verify their outcomes.

\subsection{Participants}

Twelve (12) 3D hand scans chosen for this study were part of a more extensive database taken by the Human Dimensioning Lab at the University of Minnesota. Participants for this database were recruited at the 2019 Minnesota State Fair through the Driven to Discover (D2D) research program. The database included basic demographic information and manual hand breadth data for each participant. The study's inclusion was based on a stratified sample of participants representing a distribution of $95 \%$ to $5 \%$ measurements of hand breadth. Hand breadth was determined based on the summary statistics provided by the ANSUR II database [11]. The final demographics for the participants represent a range of hand breadth chosen to cover over $95 \%$ and under $5 \%$. This study included six (6) male and six (6) female participants between the ages of 16 and 64 of Caucasian and Asian descent.

The twelve (12) three-dimensional hand scans were printed with a Creality CR-10 three-dimensional printer using white PLA materials.

\subsection{Landmarking}

Fourteen (14) total landmarks were placed at anatomical locations on the 3D printed hands using blue $0.125 "$ diameter circular dot stickers. The landmarking procedures are adapted from Griffin, Sokolowski, Lee, Seifert, Kim, \& Carufel (2018) [7] and locations were identified through literature and previous anthropometric studies $[11,12,13,14,15]$.

\subsection{Tools}

\subsubsection{D Scanners}

This study examined two (2) full-color hand-held 3D scanners (the Occipital Structure Sensor and Artec Leo). The Occipital Structure Sensor works with an iPad and can capture anatomical scans of the hand in roughly 1.5 to 2.5 minutes. The Artec Leo offers automatic onboarding processing and can capture anatomical scans in roughly 1 minute.

\subsubsection{The Post-Processing Visual Analysis Likert Scale}

The Post-Processing Visual Analysis Likert Scale, developed by Juhnke, Pokorny, and Griffin (2021) [1], was modified and used to compare the scans for 3D Visual Reliability Analysis and 3D Precision Analysis. The Post-Processing Visual Analysis Likert Scale [1] provided clear definitions for each location to quantify the scans' overall quality within the visual assessment. Quantification occurs in this Likert scale through rating the hand one (1) to five (5), with one (1) being the lowest quality and five (5) being the highest quality. There are three (3) areas of interest when assessing a 3D scan: hand visibility, webbing, and landmarking. Each of these areas was then split up into locations when evaluating the quality of the 3D hand scan for digital measuring. Detailed descriptions of each quantification measurement are listed for each location in Table 1. 
Table 1. Post-Processing Visual Analysis Likert Scale [1].

\begin{tabular}{|c|c|c|c|c|c|c|}
\hline $\begin{array}{c}\text { Visual } \\
\text { Analysis }\end{array}$ & Location & 1 & 2 & 3 & 4 & 5 \\
\hline \multirow[t]{3}{*}{$\begin{array}{c}\text { Hand } \\
\text { Visibility }\end{array}$} & $\begin{array}{c}\text { Dorsal Side } \\
\text { of Hand }\end{array}$ & $\begin{array}{l}\text { The entire dorsal } \\
\text { side of the hand } \\
\text { is distorted }\end{array}$ & $\begin{array}{c}75 \% \text { of the } \\
\text { dorsal side of the } \\
\text { hand is distorted }\end{array}$ & $\begin{array}{l}50 \% \text { of the } \\
\text { dorsal side of the } \\
\text { hand is distorted }\end{array}$ & $\begin{array}{c}25 \% \text { of the } \\
\text { dorsal side of the } \\
\text { hand is distorted }\end{array}$ & $\begin{array}{l}\text { The dorsal side } \\
\text { of the hand is } \\
\text { clear of any } \\
\text { distortions and } \\
\text { appears realistic } \\
\text { to the human } \\
\text { hand }\end{array}$ \\
\hline & $\begin{array}{c}\text { Palmar Side } \\
\text { of Hand }\end{array}$ & $\begin{array}{l}\text { The entire } \\
\text { palmar side of } \\
\text { the hand is } \\
\text { distorted }\end{array}$ & $\begin{array}{l}75 \% \text { of the } \\
\text { palmar side of } \\
\text { the hand is } \\
\text { distorted }\end{array}$ & $\begin{array}{l}50 \% \text { of the } \\
\text { palmar side of } \\
\text { the hand is } \\
\text { distorted }\end{array}$ & $\begin{array}{l}25 \% \text { of the } \\
\text { palmar side of } \\
\text { the hand is } \\
\text { distorted }\end{array}$ & $\begin{array}{l}\text { The palmar side } \\
\text { of hand is clear } \\
\text { of any distortions } \\
\text { and appears } \\
\text { realistic to the } \\
\text { human hand }\end{array}$ \\
\hline & $\begin{array}{c}\text { Clarity of } \\
\text { Digit Shape } \\
\end{array}$ & $\begin{array}{c}5 \text { digits are } \\
\text { distorted }\end{array}$ & $\begin{array}{c}4 \text { digits are } \\
\text { distorted }\end{array}$ & $\begin{array}{c}2-3 \text { digits are } \\
\text { distorted }\end{array}$ & $\begin{array}{l}1 \text { digit is } \\
\text { distorted }\end{array}$ & $\begin{array}{c}\text { No digits are } \\
\text { distorted }\end{array}$ \\
\hline \multirow[t]{5}{*}{ Webbing } & $\begin{array}{l}\text { Quantity of } \\
\text { Digits with } \\
\text { Webbing }\end{array}$ & $\begin{array}{l}\text { Webbing is } \\
\text { present between } \\
\text { all digits }\end{array}$ & $\begin{array}{c}\text { Webbing is } \\
\text { present between } \\
3 \text { sets of digits }\end{array}$ & $\begin{array}{l}\text { Webbing is } \\
\text { present between } \\
2 \text { sets of digits }\end{array}$ & $\begin{array}{c}\text { Webbing is } \\
\text { present between } \\
1 \text { set of digits }\end{array}$ & $\begin{array}{c}\text { Webbing } \\
\text { between digits } \\
\text { appears realistic } \\
\text { to the human } \\
\text { hand }\end{array}$ \\
\hline & $\begin{array}{c}\text { Amount of } \\
\text { Webbing } \\
\text { between } \\
\text { Digits } 1 \text { and } \\
2\end{array}$ & $\begin{array}{c}\text { Webbing } \\
\text { extends past the } \\
\text { proximal } \\
\text { interphalangeal } \\
\text { joint }\end{array}$ & $\begin{array}{l}\text { Webbing exists } \\
\text { at or near the } \\
\text { proximal } \\
\text { interphalangeal } \\
\text { joint }\end{array}$ & $\begin{array}{l}\text { Webbing exists } \\
\text { between the } \\
\text { metacarpal } \\
\text { phalangeal joint } \\
\text { and proximal } \\
\text { interphalangeal } \\
\text { joint }\end{array}$ & $\begin{array}{l}\text { Webbing exists } \\
\text { near the } \\
\text { metacarpal } \\
\text { phalangeal joint }\end{array}$ & $\begin{array}{c}\text { Webbing } \\
\text { between digits } \\
\text { appears realistic } \\
\text { to the human } \\
\text { hand }\end{array}$ \\
\hline & $\begin{array}{c}\text { Amount of } \\
\text { Webbing } \\
\text { between } \\
\text { Digits } 2 \text { and } \\
3\end{array}$ & $\begin{array}{c}\text { Webbing } \\
\text { extends past the } \\
\text { distal } \\
\text { interphalangeal } \\
\text { joint }\end{array}$ & $\begin{array}{l}\text { Webbing } \\
\text { between } \\
\text { proximal and } \\
\text { distal } \\
\text { interphalangeal } \\
\text { joint }\end{array}$ & $\begin{array}{l}\text { Webbing exists } \\
\text { at or near the } \\
\text { proximal } \\
\text { interphalangeal } \\
\text { joint }\end{array}$ & $\begin{array}{l}\text { Webbing exists } \\
\text { between the } \\
\text { metacarpal } \\
\text { phalangeal joint } \\
\text { and proximal } \\
\text { interphalangeal } \\
\text { joint }\end{array}$ & $\begin{array}{c}\text { Webbing } \\
\text { between digits } \\
\text { appears realistic } \\
\text { to the human } \\
\text { hand }\end{array}$ \\
\hline & $\begin{array}{c}\text { Amount of } \\
\text { Webbing } \\
\text { between } \\
\text { Digits } 3 \text { and } \\
4\end{array}$ & $\begin{array}{c}\text { Webbing } \\
\text { extends past the } \\
\text { distal } \\
\text { interphalangeal } \\
\text { joint }\end{array}$ & $\begin{array}{c}\text { Webbing } \\
\text { between } \\
\text { proximal and } \\
\text { distal } \\
\text { interphalangeal } \\
\text { joint }\end{array}$ & $\begin{array}{l}\text { Webbing exists } \\
\text { at or near the } \\
\text { proximal } \\
\text { interphalangeal } \\
\text { joint }\end{array}$ & $\begin{array}{l}\text { Webbing exists } \\
\text { between the } \\
\text { metacarpal } \\
\text { phalangeal joint } \\
\text { and proximal } \\
\text { interphalangeal } \\
\text { joint }\end{array}$ & $\begin{array}{c}\text { Webbing } \\
\text { between digits } \\
\text { appears realistic } \\
\text { to the human } \\
\text { hand }\end{array}$ \\
\hline & $\begin{array}{l}\text { Amount of } \\
\text { Webbing } \\
\text { between } \\
\text { Digits } 4 \text { and } \\
5\end{array}$ & $\begin{array}{c}\text { Webbing } \\
\text { extends at or } \\
\text { past the distal } \\
\text { interphalangeal } \\
\text { joint }\end{array}$ & $\begin{array}{c}\text { Webbing } \\
\text { between } \\
\text { proximal and } \\
\text { distal } \\
\text { interphalangeal } \\
\text { joint }\end{array}$ & $\begin{array}{l}\text { Webbing exists } \\
\text { at or near the } \\
\text { proximal } \\
\text { interphalangeal } \\
\text { joint }\end{array}$ & $\begin{array}{l}\text { Webbing exists } \\
\text { between the } \\
\text { metacarpal } \\
\text { phalangeal joint } \\
\text { and proximal } \\
\text { interphalangeal } \\
\text { joint }\end{array}$ & $\begin{array}{c}\text { Webbing } \\
\text { between digits } \\
\text { appears realistic } \\
\text { to the human } \\
\text { hand }\end{array}$ \\
\hline \multirow[t]{2}{*}{$\underset{\left({ }^{*}\right)}{\operatorname{Landmark}}$} & $\begin{array}{l}\text { Visibility of } \\
\text { Landmarks }\end{array}$ & $\begin{array}{c}7 \text { of the } \\
\text { landmarks are } \\
\text { visible }\end{array}$ & $\begin{array}{c}8 \text { or } 9 \text { of the } \\
\text { landmarks are } \\
\text { visible }\end{array}$ & $\begin{array}{c}11 \text { or } 10 \text { of the } \\
\text { landmarks are } \\
\text { visible }\end{array}$ & $\begin{array}{c}12 \text { or } 13 \text { of the } \\
\text { landmarks are } \\
\text { visible }\end{array}$ & $\begin{array}{c}\text { All } 14 \text { of the } \\
\text { landmarks are } \\
\text { visible }\end{array}$ \\
\hline & $\begin{array}{l}\text { Clarity of } \\
\text { Visible } \\
\text { Landmarks }\end{array}$ & $\begin{array}{c}6 \text { or more of the } \\
\text { visible } \\
\text { landmarks are } \\
\text { distorted }\end{array}$ & $\begin{array}{c}\text { 4-5 of the visible } \\
\text { landmarks are } \\
\text { distorted }\end{array}$ & $\begin{array}{c}\text { 2-3 of the visible } \\
\text { landmarks are } \\
\text { distorted }\end{array}$ & $\begin{array}{c}1 \text { of the visible } \\
\text { landmarks is } \\
\text { distorted }\end{array}$ & $\begin{array}{l}\text { No distortion } \\
\text { seen in visible } \\
\text { landmarks }\end{array}$ \\
\hline
\end{tabular}

$\left(^{*}\right)$ Not a form of measurement for the original 3D scan. 


\subsection{Analysis of Data}

Three scans were taken for each participant using the two (2) full-color hand-held 3D scanners (the Occipital Structure Sensor and Artec Leo). The scans from the Occipital Structure Sensor go through automatic processing in the SDK scanning application software. The files were then taken into Meshmixer for minimal editing to delete the scanning platform. The Artec Leo's scans are exported from the Artec Leo and imported into Artec Studio 14 Professional Software. Artec Studio 14 Professional Software is then used for manual processing and minimal editing to delete the scanning platform.

Once editing was complete, 3D Visual Reliability Analysis took place, which examines the ability of each scanner to capture the 3D scan consistently. The 3D Visual Reliability Analysis consisted of assessing three (3) scans taken with the Occipital Structure Sensor, and three (3) scans taken with the Artec Leo, for each participant using the Post-Processing Visual Analysis Likert Scale [1] (see Fig. 1).

Based on the results of the 3D Visual Reliability Analysis final scans were chosen for each participant from the Occipital Structure Sensor and Artec Leo to move onto the 3D Visual Precision Analysis

The 3D Visual Precision Analysis examines the exactness and accuracy of the final scans used for digital measuring. The assessment was completed by comparing the original 3D scan used to create the 3D printed model, the final scans taken with the Occipital Structure Sensor, and the final scans taken with the Artec Leo using the Post-Processing Visual Analysis Likert Scale [1] (see Fig. 1).
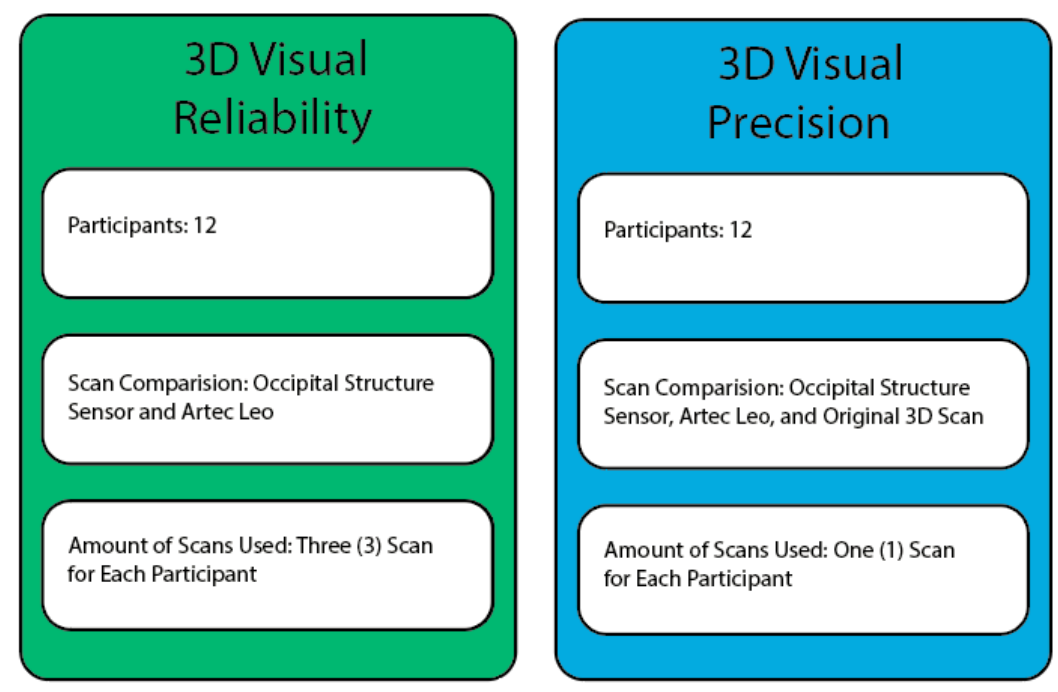

Fig. 1. Overview of Visual Analysis.

The 3D Visual Reliability Analysis's statistical analysis assists will include descriptive statistics, including mean and standard deviation. The significance of the differences among the different means of each hand measurement from the two (2) methods (Occipital Structure Sensor and Artec Leo) will be reported via One-Way ANOVA $(\mathrm{p}<0.05)$. Post-Hoc Pairwise Analysis will take place for the measurements showing statistical significance from the One-Way ANOVA using Tukey Honestly Significant Difference (HSD) Method.

The 3D Visual Precision Analysis's statistical analysis will include descriptive statistics, including mean and standard deviation. The significance of the differences among the different means of each hand measurement from the three (3) methods (Occipital Structure Sensor, Artec Leo, and the original scans used for the 3D printed model) will be reported via One-Way ANOVA $(p<0.05)$. Post-Hoc Pairwise Analysis will take place for the measurements showing statistical significance from the One-Way ANOVA using Tukey Honestly Significant Difference (HSD) Method. 


\section{Results}

\subsection{D Visual Reliability Analysis}

On average, the scores for the Occipital Structure Sensor $(O)$ were higher at the Hand Visibility and Webbing locations compared to the Artec Leo (A). The greatest differences between the two (2) 3D scanners (Occipital Structure Sensor $(\mathrm{O})$ and Artec Leo (A)) occurred at the Landmark locations. The Artec Leo (A) scored higher on average for both Landmark locations compared to the Occipital Structure Sensor (O) (see Table 2).

Table 2. 3D Visual Reliability Analysis Descriptive Statistics.

\begin{tabular}{|c|c|c|c|c|c|}
\hline \multirow{4}{*}{ Visual Analysis } & Location & \multicolumn{2}{|c|}{ O } & \multicolumn{3}{c|}{ A } \\
\cline { 2 - 6 } & & Mean & SD & Mean & SD \\
\hline \multirow{4}{*}{ Hand Visibility } & Dorsal Side of Hand & 5 & 0 & 4.97 & 0.17 \\
\cline { 2 - 6 } & Palmar Side of Hand & 4.18 & 0.95 & 3.96 & 0.94 \\
\cline { 2 - 6 } & Clarity of Finger Shape & 2.58 & 0.77 & 2.53 & 0.74 \\
\hline \multirow{5}{*}{ Webbing } & Quantity of Fingers with Webbing & 3.25 & 0.6 & 3.17 & 0.56 \\
\cline { 2 - 6 } & Amount of Webbing between Digits 1 and 2 & 4.92 & 0.28 & 4.92 & 0.28 \\
\cline { 2 - 6 } & Amount of Webbing between Digits 2 and 3 & 3.89 & 0.89 & 3.81 & 0.98 \\
\cline { 2 - 6 } & Amount of Webbing between Digits 3 and 4 & 2.47 & 1.13 & 2.64 & 1.2 \\
\cline { 2 - 6 } & Amount of Webbing between Digits 4 and 5 & 5 & 0 & 5 & 0 \\
\hline \multirow{3}{*}{ Landmarks (^) } & Visibility of Landmarks & 4.03 & 0.65 & 4.81 & 0.4 \\
\cline { 2 - 6 } & Clarity of Visible Landmarks & 3.5 & 1.21 & 3.94 & 0.89 \\
\hline
\end{tabular}

$\left(^{\wedge}\right)$ Not a form of measurement for the original 3D scan. 
A One-Way ANOVA revealed statistically significant between group differences occurred at the Visibility of Landmarks $(F(1,70)=36.98, p=5.63 e-08)$ location (see Table 3).

Table 3. 3D Visual Reliability Analysis One-Way ANOVA.

\begin{tabular}{|c|c|c|c|c|}
\hline Visual Analysis & Location & Df & F & Sig. \\
\hline \multirow{5}{*}{ Hand Visibility } & Dorsal Side of the Hand & 2,81 & 0.661 & 0.519 \\
\cline { 2 - 5 } & Palmar Side of the Hand & 2,81 & 0.974 & 0.382 \\
\cline { 2 - 5 } & Clarity of Finger Shape & 2,81 & 0.07 & 0.933 \\
\hline \multirow{7}{*}{ Webbing } & Quantity of Fingers with Webbing & 2,81 & 0.407 & 0.667 \\
\cline { 2 - 5 } & Amount of Webbing between Digits 1 and 2 & 2,81 & 0 & 1 \\
\cline { 2 - 5 } & Amount of Webbing between Digits 2 and 3 & 2,81 & 1.571 & 0.214 \\
\cline { 2 - 5 } & Amount of Webbing between Digits 3 and 4 & 2,81 & 0.956 & 0.389 \\
\cline { 2 - 5 } & Amount of Webbing between Digits 4 and 5 & 2,81 & 0.661 & 0.519 \\
\hline \multirow{3}{*}{ Landmarks (^) } & Visibility of Landmarks & 1,70 & 36.98 & $5.63 e-08$ *** \\
\cline { 2 - 5 } & Clarity of Visible Landmarks & 1,70 & 3.155 & 0.08 \\
\hline
\end{tabular}

$\left({ }^{\wedge}\right)$ Not a form of measurement for the original 3D scan.

*Significant at the .05 level

** Significant at the .01 level

*** Significant at the .00 level

A post-hoc comparison revealed that statistically significant differences occurred between the Occipital Structure Sensor and the Artec Leo (O vs A) at the Visibility of Landmarks ( $p=1 \mathrm{e}-07$ ) location (see Table 4).

Table 4. 3D Visual Reliability Analysis Post-Hoc Pairwise Analysis using Tukey Honestly Significant Difference (HSD) Method.

\begin{tabular}{|c|c|c|c|}
\hline \multirow{2}{*}{ Visibility of Landmarks } & \multirow{2}{*}{ Sig. } & \multicolumn{2}{|c|}{$95 \%$ Confidence Interval } \\
\cline { 3 - 4 } & & Lower Bound & Upper Bound \\
\hline O vs A & $1 \mathrm{e}-07$ & -1.032863 & -0.5226923 \\
\hline
\end{tabular}

\subsection{D Visual Precision Analysis}

On average, the scores for the original 3D scan used to create the 3D printed model (TPH) were higher at the Hand Visibility and Webbing locations compared to the two (2) 3D scanners (Occipital Structure Sensor (O) and Artec Leo (A)). Between the two (2) 3D scanners (Occipital Structure Sensor (O) and Artec Leo (A)) the averages were similar at the Hand Visibility and Webbing locations. The greatest differences between the two (2) 3D scanners (Occipital Structure Sensor (O) and Artec Leo (A)) occurred at the Landmark locations. The Artec Leo (A) scored higher on average for both Landmark locations compared to the Occipital Structure Sensor (O) (see Table 5). 
Table 5. 3D Visual Precision Analysis Descriptive Statistics.

\begin{tabular}{|c|c|c|c|c|c|c|c|}
\hline \multirow[t]{2}{*}{ Visual Analysis } & \multirow[t]{2}{*}{ Location } & \multicolumn{2}{|c|}{0} & \multicolumn{2}{|c|}{ A } & \multicolumn{2}{|c|}{ TPH } \\
\hline & & Mean & SD & Mean & SD & Mean & SD \\
\hline \multirow[t]{3}{*}{ Hand Visibility } & Dorsal Side of Hand & 5 & 0 & 5 & 0 & 5 & 0 \\
\hline & Palmar Side of Hand & 4.21 & 0.99 & 3.96 & 0.96 & 3.79 & 0.84 \\
\hline & Clarity of Finger Shape & 2.58 & 0.79 & 2.58 & 0.67 & 2.5 & 1 \\
\hline \multirow[t]{5}{*}{ Webbing } & Quantity of Fingers with Webbing & 3.25 & 0.62 & 3.17 & 0.58 & 3.33 & 0.65 \\
\hline & Amount of Webbing between Digits 1 and 2 & 4.92 & 0.29 & 4.92 & 0.29 & 4.92 & 0.29 \\
\hline & Amount of Webbing between Digits 2 and 3 & 4 & 0.74 & 3.83 & 0.94 & 4.33 & 0.65 \\
\hline & Amount of Webbing between Digits 3 and 4 & 2.5 & 1.17 & 2.67 & 1.23 & 3 & 1.04 \\
\hline & Amount of Webbing between Digits 4 and 5 & 5 & 0 & 5 & 0 & 5 & 0 \\
\hline \multirow[t]{2}{*}{ Landmarks $(\wedge)$} & Visibility of Landmarks & 4.33 & 0.65 & 5 & 0 & $\mathrm{~N} / \mathrm{A}$ & $\mathrm{N} / \mathrm{A}$ \\
\hline & Clarity of Visible Landmarks & 3.83 & 1.19 & 4.33 & 0.78 & $\mathrm{~N} / \mathrm{A}$ & $\mathrm{N} / \mathrm{A}$ \\
\hline
\end{tabular}

$\left(^{\wedge}\right)$ Not a form of measurement for the original 3D scan.

A One-Way ANOVA revealed statistically significant between group differences occurred at the Visibility of Landmarks $(F(1,22)=12.57, p=0.00181)$ location (see Table 6).

Table 6. 3D Visual Precision Analysis One-Way ANOVA.

\begin{tabular}{|c|c|c|c|c|}
\hline Visual Analysis & Location & Df & F & Sig. \\
\hline \multirow{4}{*}{ Hand Visibility } & Dorsal Side of Hand & 2,33 & 1 & 0.379 \\
\cline { 2 - 5 } & Palmar Side of Hand & 2,33 & 0.607 & 0.551 \\
\cline { 2 - 5 } & Clarity of Finger Shape & 2,33 & 0.04 & 0.961 \\
\hline \multirow{4}{*}{ Webbing } & Quantity of Fingers with Webbing & 2,33 & 0.219 & 0.805 \\
\cline { 2 - 5 } & Amount of Webbing between Digits 1 and 2 & 2,33 & 0 & 1 \\
\cline { 2 - 6 } & Amount of Webbing between Digits 2 and 3 & 2,33 & 1.262 & 0.296 \\
\cline { 2 - 5 } & Amount of Webbing between Digits 3 and 4 & 2,33 & 0.588 & 0.561 \\
\cline { 2 - 5 } & Amount of Webbing between Digits 4 and 5 & 2,33 & 1 & 0.379 \\
\hline \multirow{2}{*}{ Landmarks (^) } & Visibility of Landmarks & 1,22 & 12.57 & $0.00181^{* *}$ \\
\cline { 2 - 5 } & Clarity of Visible Landmarks & 1,22 & 1.478 & 0.237 \\
\hline
\end{tabular}

${ }^{\wedge}$ ) Not a form of measurement for the original 3D scan.

*Significant at the .05 level

** Significant at the .01 level 
A post-hoc comparison revealed that statistically significant differences occurred between the Occipital Structure Sensor and the Artec Leo ( $O$ vs $A)$ at the Visibility of Landmarks $(p=0.001814$ ) location (see Table 7).

Table 7. 3D Visual Precision Analysis Post-Hoc Pairwise Analysis using Tukey Honestly Significant Difference (HSD) Method.

\begin{tabular}{|c|c|c|c|}
\hline \multirow{2}{*}{ Visibility of Landmarks } & \multirow{2}{*}{ P-adj } & \multicolumn{2}{|c|}{ 95\% Confidence Interval } \\
\cline { 3 - 4 } & & Lower Bound & Upper Bound \\
\hline O vs A & 0.001814 & -1.056607 & -0.276726 \\
\hline
\end{tabular}

\section{Discussion and Conclusion}

\subsection{Overview}

The results from this study led to a review to quantify where landmark visibility issues occurred for the final scans from the Occipital Structure Sensor. Six (6) out of twelve (12) scans had incomplete landmarking at the Fingertips of Digits 2 and 3 locations. Visible landmarks occurred at P1, P2, P7, P10, P11, and P12 (see Fig. 2). When scans are missing landmarks, the measurer has two options moving forward: independent identification of landmarking or eliminating the participants from the impacted measurements to ensure the comparison of similar datasets.
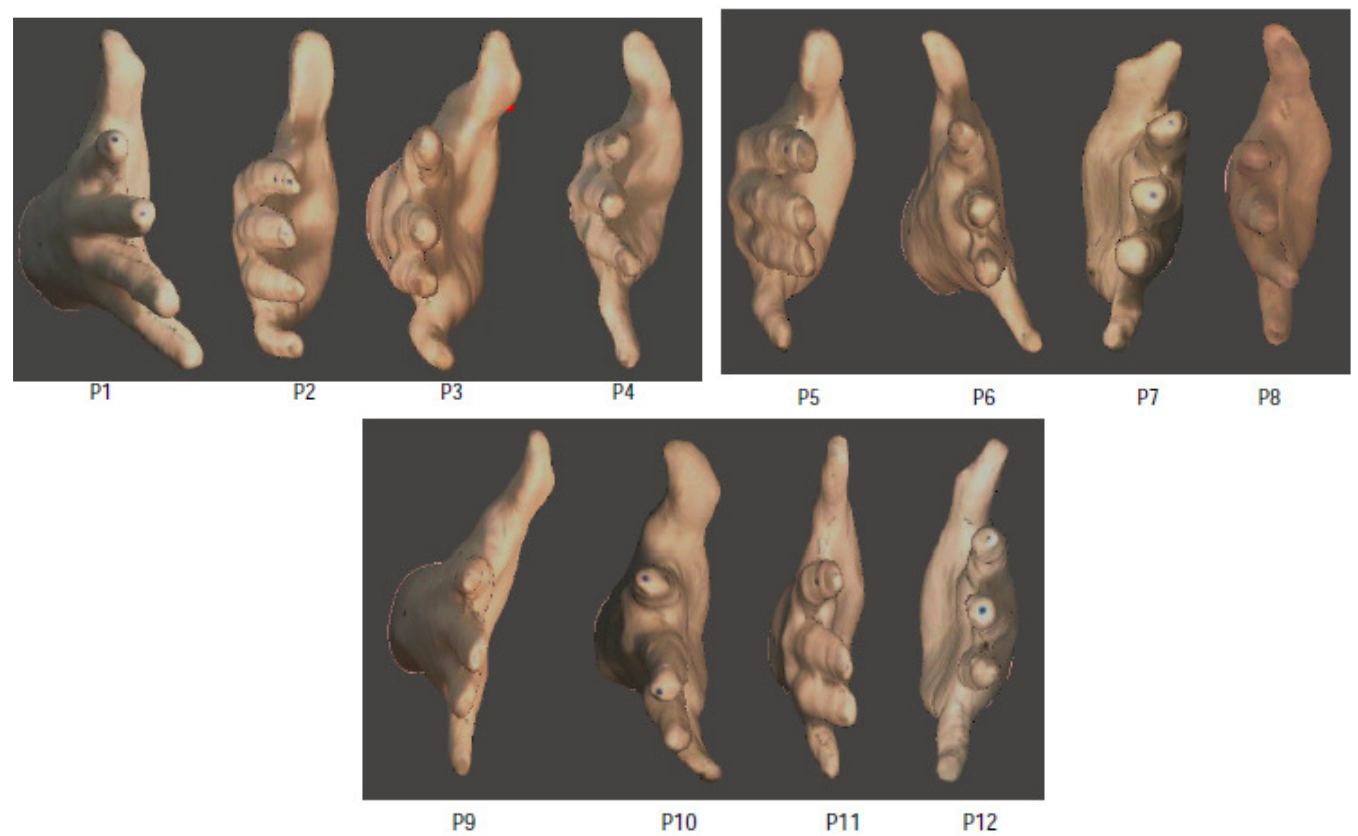

Fig. 2. Visual Analysis of the Fingertips of Digits 2 and 3.

\subsection{Limitations and Future Research}

The twelve (12) 3D hand scans were printed using white PLA materials. The ability for both 3D scanners (the Occipital Structure Sensor and the Artec Leo) to capture a wide variety of skin colors is essential to developing products that interact with the hand [10]. Since statistically significant differences occurred at the Visibility of Landmarks location for the two (2) visual analyses with the white PLA material, both the Visibility and Clarity of Landmarks need to be assessed with a range of various skin colors.

The participants' demographics from the original 3D scans chosen for this study did not reflect a racially diverse database. In the future, comparing racially diverse participants will be included. 
This study shows that further testing is needed with the Occipital Structure Sensor at various angles to examine if landmark capture could be improved.

The inclusion of the selection of missing landmarks for each scan during the Post-Processing Visual Analysis Likert Scale [1] could assist in being able to quantify where incomplete landmark capture is occurring without having to go back to review the scans.

The Post-Processing Visual Analysis Likert Scale [1] was completed by one researcher. Inter-rater reliability needs to be compared to ensure the validity of this tool.

\subsection{Implications and Conclusion}

Within this study, a Post-Processing Visual Analysis Likert Scale [1], previously used to visually analyze scans within data collection, provided clear definitions for three locations (hand visibility, webbing, and landmarking) to quantify the overall quality of the scans within the visual assessment.

An evaluation should take place to classify the number of deformities and at what location they can occur on 3D hand scans with minimal impact on anthropometric hand measurement. The use of visual analysis as a form of evaluation for the validation of $3 \mathrm{D}$ scanners is crucial to understanding where the scan's quality might affect the outcomes from the data collection.

\section{References}

[1] B. Juhnke, C. Pokorny, and L. Griffin, "Standardized Functional Hand Grasp Method Development for 3D Scanning," in Journal Article for International Journal of Industrial Ergonomics, Under review, 2021.

[2] Z. Li, C. C. Chang, P. G. Dempsey, L. Ouyang, and J. Duan, "Validation of a three-dimensional hand scanning and dimension extraction method with dimension data," Ergonomics, vol. 51, no.11, pp. 1672-1692, Nov. 2008, https://doi.org/10.1080/00140130802287280.

[3] A. Klepser, M. Babin, C. Loercher, F. Kirchdoerfer, J. Beringer, \& A. Schmidt, "3D Hand Measuring with a Mobile Scanning System," in Proc. of 3rd Int. Conf. on 3D Body Scanning Technologies, Lugano, Switzerland, 2012, pp. 288-294, https://doi.org/10.15221/12.288.

[4] A. Yu, K. L. Yick, S. P. Ng, and J. Yip, "2D and 3D anatomical analyses of hand dimensions for custom-made gloves," in Applied Ergonomics, vol. 44, no. 3, pp. 381-392, May 2013, https://doi.org/10.1016/j.apergo.2012.10.001.

[5] S. H. Nasir, O. Troynikov, \& C. Watson, "Skin deformation behavior during hand movements and their impact on functional sports glove design," in Procedia Engineering, vol. 112, pp. 92-97, 2015, https://doi.org/10.1016/j.proeng.2015.07.181.

[6] I. A. Hoevenaren, T. J. Maal, E. Krikken, A. F. J. De Haan, S. J. Bergé, \& D. J. O. Ulrich, "Development of a three-dimensional hand model using 3D stereophotogrammetry: evaluation of landmark reproducibility," in Journal of Plastic, Reconstructive \& Aesthetic Surgery, vol. 68, no.5, pp. 709-716, 2015, https://doi.org/10.1016/i.bjps.2014.12.025.

[7] L. Griffin, S. Sokolowski, H. Lee, E. Seifert, N. Kim, and R. Carufel, "Methods and tools for 3D measurement of hands and feet," in International Conference on Applied Human Factors and Ergonomics, pp. 49-58, Springer, Cham, July 2018, https://doi.org/10.1007/978-3-319-94601- 6_7.

[8] C. Pokorny, E. Seifert, L. Griffin, B. Holschuh, B. Juhnke, \& E. Savvateev, "Validation of the Artec Eva for Hand Anthropometric Data Collection", in International Textile and Apparel Association Annual Conference Proceedings, 2019, https://doi.org/10.31274/itaa.8376.

[9] B. J. Dunbar and P. J. Chapates, "Comparison of 3D photogrammetric and laser hand scans to manual measurement methods for EVA glove fabrication," in 2019 IEEE Aerospace Conference, pp. 1-11, 2019, https://doi.org/10.1109/AERO.2019.8742197

[10] S. L. Sokolowski, L. Griffin, and S. Chandrasekhar, "Current technology landscape for collecting hand anthropometric data," in 9th International Conference and Exhibition on 3D Body Scanning and Processing Technologies, pp. 142-153, Oct. 2018, https://doi.org/10.15221/18.142. 
[11] C. C. Gordon, C. L. Blackwell, B. Bradtmiller, J. L. Parham, P. Barrientos, S. P. Paquette, B. D. Corner, J. M. Carson, J. C. Venezia, B. M. Rockwell, M. Mucher, and S. Kristensen, "Anthropometric Survey of US Army Personnel: Methods and Summary Statistics," ARMY NATICK SOLDIER RESEARCH DEVELOPMENT AND ENGINEERING CENTER MA, Rep. NATICK/TR-15/007, 2012.

[12] R. M. White, "Comparative Anthropometry of the Hand," Army Natick Research and Development Labs Ma Clothing Equipment and Materials Engineering Lab, Rep. NATICK/CEMEL-229, 1980.

[13] C.C. Gordon, T. Churchill, C.E. Clauser, B. Bradtmiller, J. T. McConville, I. Tebbetts, and R.A. Walker, "Anthropometric survey of US Army personnel: summary statistics, interim report for 1988," ANTHROPOLOGY RESEARCH PROJECT INC YELLOW SPRINGS OH, 1989.

[14] T. M. Greiner, "Hand anthropometry of US army personnel," ARMY NATICK RESEARCH DEVELOPMENT AND ENGINEERING CENTER MA, Rep. TR-92/011, 1991.

[15] K. M. Robinette, S. Blackwell, H. Daanen, M. Boehmer, and S. Fleming, "Civilian American and European Surface Anthropometry Resource (CAESAR), Final Report. Volume 1. Summary", SYTRONICS INC DAYTON OH, 2002. 